\title{
Dossiê
}

Resumo

Trata do contexto concreto em que uma Bolsa foi denegada, apesar dos equivocos do parecer a respeito da metodologia (análise institucional do discurso), uma vez que esta não contempla a teoria psicanalítica, quando o discurso em análise é o do Homem dos Lobos, de Freud. São reunidos argumentos, a partir da concepcáa de discurso como ato, acontecimento e como instituição, para afirmar o estranbamento como condição de análise; talvez, seu limite inevitável. Torna-se, assim, possivel, continuar pensando, apesar dos efeitos imediatos desses procedimentos de avaliação em/de nossa produção intelectual.

Descritores: análise do discurso; psicanálise; poder; verdade.

\section{UMA ANÁLISE POSSÍVEL DO DISCURSO DA PSICANÁLISE}

\author{
Marlene Guirado
}

E

4 ste texto bem poderia ter outro título: Em defesa de uma análise não psicanalítica do discurso da psicanálise. $\mathrm{Ou}$, ainda: Por uma análise institucional do discurso da psicanálise.

Por prometerem muito, sobretudo no que diz respeito à abrangência dos discursos da psicanálise em foco, optei pelo termo possivel, para restringir o âmbito da análise em pauta. $\mathrm{O}$ artigo indefinido (uma análise...) já indica restrição. Mas será, por extensão, na relação entre todos os termos, que se atingirá o corpus-alvo da discussão e da argumentação que se pretende construir, no decorrer de umas poucas páginas.

É importante, ainda, que se enunciem os interlocutores, os provocadores concretos de mais esta escritura. São eles os comentadores dos trabalhos que têm sido produzidos com a Análise Institucional do Discurso, uma estratégia de pensamento, um método, um modo de fazer e pensar a psicologia, na 
interface da psicanálise de Freud, da análise pragmática do discurso de orientação francesa (de Dominique Maingueneau) e as ideias de M. Foucault.

Tais interlocuções se dão, ora no contexto aberto e imediato de debates científicos ou de bancas de teses e dissertações, ora no contexto de agências de fomento à pesquisa ou de revistas indexadas, quando os pareceres são via de mão única, protegidas que estão, pelo sigilo de fonte, suas autorias.

Apesar de estes contextos serem sempre de caráter avaliativo da produção em questão, cabem algumas palavras a mais a respeito daqueles que, sob sigilo, conferem poder de veto ou de classificação/eliminação aos pareceres. Afinal, cada vez mais, nos vemos compelidos (nós, professores universitários e pesquisadores) a expor nossos trabalhos, diretamente ou por solicitações de auxílios a orientandos, porque isso nos tem sido exigido como índice de produção acadêmica: tem sido parte de procedimentos de avaliação de nossas condições intelectuais, das condições dos Departamentos de Ensino e dos Programas de Pós-Graduação (que recebem notas e, conforme as notas, benefícios para os Programas e para os alunos).

Não é o espaço, nem o momento, para discutir a justeza desses critérios, seu caráter burocrático, esvaziado de atenções qualitativas e voltado a modelos presumíveis, prontos, nu- méricos e considerados mais objetivos, na definição dos graus de aproximação/distância de alvos também previamente definidos; alvos e critérios que nem sempre dão conta da complexidade das questões que dizem abranger (como as sociais, culturais ou do tipo de conhecimento em jogo, só para dar alguns exemplos dos problemas que, aqui e ali, ouve-se, são negligenciados pelas instâncias de avaliação e fomento do trabalho acadêmico).

O parágrafo acima aponta para os temas de conflito, para pontos de tensão, entre instâncias em oposição: avaliados e avaliadores. Não propriamente as pessoas, mas essas posições em exercício constante, de desempenhos em apreciação e de desempenhos de apreciação. Ação de adestramento constante da ação de ser professor ou pesquisador nas universidades deste país.

Se não prosseguimos nessa direção, neste momento e neste texto, é porque decidimos assumir uma dessas posições; no caso, a de quem, malgrado suas resistências e no exíguo cumprimento de exigências heterônomas, expõe seu trabalho ao "controle de qualidade", à ação de colegas na posição de avaliadores.

Nenhuma ilusão, no entanto, quanto à isenção política ou moral de (não ou só) ocupar este ou aquele lugar. As pessoas que são avaliadas, em outros momentos, avaliam. Trata-se de procedimentos, de discursos, que submetem subjetividades. E esses 
procedimentos, portanto, é que deveriam ser o alvo de algum tipo de irritação ou mobilização que descompensasse, para além do suportável, o jogo de forças.

Ultrapassando suas atenções específicas, este texto, no ato de sua escritura, inscreve-se como uma provocação desses procedimentos. Por quê?

Na qualidade de professora, pesquisadora e orientadora de pesquisas, faço parte desse jogo. Ao escrever em defesa de um modo de analisar o discurso da psicanálise; ao escrever, rebatendo comentários feitos sobre o método que vimos organizando para trabalhar com a psicologia na interface com outras áreas do conhecimento; ao escrever visando a um interlocutor que não se colocou nessa posição, pois não há qualquer expectativa de retorno nesses procedimentos avaliativos; ao escrever e prever mais uma vez o encaminhamento do escrito para uma das vias avaliativas da produção acadêmica (revistas especializadas e indexadas); ao escrever assim, sobre terreno complexo, num contexto que beira o paradoxo, irritamos, com certeza, as certezas dos procedimentos habituais.

Mais ainda, não nos jogamos, por autojuízo, à margem do "esquema", do "sistema" ou da disciplina que define o campo de verdades de nosso discurso da psicologia, da psicanálise, da pesquisa e da atuação profissional. Pelo contrário, buscamos reconhecimento e legitimidade para esse lugar assim, aparentemente

394 Estilos da Clínica, 2011, 16(2), 392-403 
esdrúxulo e extemporâneo, de responder a avaliações destinadas a classificar, eliminar ou incluir e ponto! Se algum efeito, ainda que mínimo, se concretizar, será o de abrir espaços para discussões novas, avanços a partir daquilo que se considerou um comentário impreciso, parcial ou equivocado. A avaliação/comentário estará, em ato, sendo avaliada/comentada. Se a tensão for maior e os efeitos mais potentes, poderemos ter o reconhecimento da legitimidade do lugar de resposta à avaliação. Dessa maneira, os efeitos se verificarão não apenas no plano do reconhecimento do conteúdo do texto, da defesa de um modo de análise, mas também na ultrapassagem das ações previstas para os mecanismos institucionais de produção da eficiência da produção do conhecimento.

É com a certeza de me mover nesses dois planos - o de argumentar em favor de uma certa modalidade de análise do discurso da psicanálise e o de, no mesmo ato, confrontar o encadeamento burocrático das avaliações no e do trabalho acadêmico - que passo, agora, ao âmbito específico desta escritura.

\section{Clrcunscrição da crítica}

Recentemente, o projeto de Iniciação Científica de um orientando ${ }^{1}$, Felipe Martins, apesar de ser bem avaliado, sobretudo quanto à importância e clareza de objetivos, não recebeu a Bolsa a que se destinara, em uma instituição de fomento. $\mathrm{O}$ motivo apresentado pelo parecerista foi o da densidade do texto freudiano, que estaria além do escopo de trabalho em uma Iniciação Científica. No quesito metodologia, porém, constava uma apreciação que não se referia especificamente ao estudo em questão e, sim, ao método ali empregado, uma espécie de comentário dirigido à orientadora, também propositora da Análise Institucional do Discurso como estratégia de pesquisa e intervenção na Psicologia. Afirma ele que a Análise Institucional do Discurso não seria um recurso metodológico adequado para o estudo de um texto clínico como o Homem dos Lobos de Freud com vistas a caracterizar, nas origens, o modo de análise da psicanálise, porque esse recurso não partiria da concepção de inconsciente e análise que investe a teoria freudiana.

Para dizer a verdade, até aí, não há muita novidade: não foi a primeira vez que críticas como essa foram feitas. Sempre, no que 
diz respeito à psicanálise, recoloca-se a demanda/exigência de que se trabalhem seus discursos, com o próprio modelo psicanalítico e com sua teoria (inclusive, como se não fossem diversos, ou melhor, como se não houvesse diferenças entre os próprios modos de saber/fazer psicanalíticos).

Esse fato já nos levou a impasses em defesas de teses. É exemplar nesse sentido, a situação em que um arguidor, psicanalista de orientação lacaniana, questionou o desenho final das análises dos discursos de profissionais sobre sua clínica, por que o pesquisador não trabalhou, diferenciando os registros imaginário e simbólico. A quadratura do círculo: como analisar, com conceitos de uma psicanálise, o discurso de profissionais que trabalham com orientações diferentes, como era o caso daquela pesquisa que confrontava os discursos de psicanalistas de formação na escola inglesa e na francesa? Impossível discutir a "simpatia imaginária" que envolveria a suposta análise do discurso dos "colegas" lacanianos, naquelas circunstâncias...

Ainda, vez ou outra, sou perguntada como que num desafio, desses de corredor de Institutos de Formação, se os psicanalistas têm reconhecido, isto é, se interessado, pela análise institucional do discurso.

Todas as formulações parecem apontar para uma espécie de inadequação da análise de discurso diante da psicanálise. Ou um descompasso.

Creio que a resposta à primeira crítica, encaminha de melhor forma, as outras. Vejamos como.

\section{O estranhamento é condição de análise. Talvez, seu limite inevitável}

À medida que alguns trabalhos em psicologia, tanto na pesquisa quanto na atuação profissional junto a instituições concretas, vêm sendo desenvolvidos na perspectiva de uma análise institucional do discurso, essa estratégia de pensar e fazer a psicologia tem ganhado terreno e gerado discussões interessantes. Sua divulgação, por meio de publicações e cursos, contribui para que isso aconteça. Com frequência, também, como era de se esperar, abrem-se espaços para equívocos, como efeito dessa visibilidade. 
Um desses equívocos gira em torno da concepção de discurso e análise.

Trabalhar analiticamente com a análise institucional do discurso implica, antes de tudo, conceber o discurso como ato; para além das palavras e de seus sentidos, implica conceber o discurso como mostração do dizer, em sua legitimidade, sua reflexividade, suas condições de enunciação (Maingueneau, 1997). De J. L. Austin (Austin, 1990) a M. Foucault (1969/1997), da filosofia da linguagem (Wittigenstein, 1952/1999) à linguística pragmática (Maingueneau, 1997 e Marcondes, 2004), o discurso e sua análise ganham autonomia das concepções de linguagem como representação da realidade e, mesmo, das concepções estruturalistas como análise da estrutura da língua na produção do enunciado, mesmo quando há atenção à enunciação.

A análise a que nos dispomos, propõe-se a configurar sentidos, sempre e somente, em função das condições de produção do discurso. Desde que se pense que estas condições (o modo de produção do discurso) não lhe são exteriores, não o antecedem, nem guardam com ele uma relação de causa-efeito e, sim, uma relação de implicação texto/contexto.

Faço-me valer de um escrito de M. Foucault, A ordem do discurso, (1999) para prosseguir argumentando em favor da análise que propomos. Trata-se da Aula Inaugural proferida por ele no Collège de France, quando da 
morte de Jean Hyppolite e do convite que recebeu para substituí-lo. Colocando-se, inicialmente, no centro de uma cena como sujeitado ao acaso do discurso, ao discurso-acontecimento, que ele ansiava que o levasse para além de todos os começos possíveis, vê-se reassegurado pelas certezas institucionais que lhe reservavam um lugar e uma direção da fala, oferecendo respostas antes mesmo que perguntas lhe ocorressem. A cena assim descrita se presta ao entendimento dos procedimentos de controle dos discursos que podem ser ditos, numa determinada época e para uma determinada região do saber; procedimentos que garantem o escopo em que se constituirão os discursos verdadeiros ou falsos; procedimentos que definem aqueles que podem dizế-los. Desse modo, a título de exemplo, separase o louco do são, para em seguida excluir o primeiro, pois escaparia do discurso verdadeiro. Ainda, as disciplinas do conhecimento, por meio de regras de como produzir para que um determinado saber possa ser considerado parte do campo das verdades possíveis, coloca como teratologia tudo o que for dito ou escrito fora dos cânones dessa produção. Os discursos que comentam e os que se pretendem originais e de autoria desenraizada, da mesma forma, constrangem o acaso e a indeterminação, que constituem para Foucault, a (temível) materialidade do discurso. E, na esfera da circulação, as sociedades de discurso, os rituais, as doutrinas e toda sorte de apropriação social e ins- titucional, ordenam a repetição do mesmo, a seleção dos que podem ser autorizados a falar, aqueles que, por sua posição, estão ungidos pelo poder e eficácia do discurso.

Isto posto, justifica-se que um discurso se coloque em análise a partir de um campo conceitual que não seja aquele construído pelos procedimentos de sua disciplina, por maquinarias e jogos que rejeitassem para lá de suas fronteiras a possibilidade de dizer verdades a outros discursos. Justifica-se uma análise que não mova a circulação das mesmas vozes e rituais, das mesmas pessoas autorizadas a dizer ou enunciar a partir de lugares marcados, nos jogos de verdade.

O discurso, pensado com Foucault, ganha uma dimensão enunciativa que aponta para a modalidade de análise que ele próprio chamou de crítico-genealógica, nesse texto: rarefeita, descritiva das positividades do discurso, para poder rastrear nele, as condições de enunciação, suspender a soberania do significante e devolverlhe a materialidade e a especificidade que lhe são características, recuperando sua dimensão de acontecimento, acaso e indeterminação (Foucault, 1999).

Pensar com esse autor o discurso e sua análise coloca-nos na posição de tomar os corpora em estudo e pesquisa, como ato, como instituições que, de alguma forma, constituíram-se num intercontexto, num interdiscurso; coloca-nos na posição de tomálos como práticas e relações de po- 
der/resistência na produção de verdades, no jogo de verdades (Foucault, 1969/1997, 2004). E isso é o que um texto escrito ou uma entrevista mostram: as interlocuções possíveis, num determinado momento e numa determinada região geográfica. Como diriam linguistas pragmáticos: um gênero de discurso, um texto no contexto (Maingueneau, 1997). Inclusive, no caso de entrevista, esse gênero deverá ser ocasião de análise, na medida em que é a condição de determinação de sentidos para o que ali for dito e reagido.

A análise institucional do discurso, já no âmbito da psicologia, se ocupará, mais especificamente, dos lugares que se configuram e exercem nessas práticas discursivas, os sujeitos aí objetivados e as subjetivações possíveis. Numa atuação direta junto a uma organização/instituição ou numa análise de texto de entrevista, por esses princípios e procedimentos, a relação de clientela, a relação com o profissional/pesquisador, ao vivo e no jogo constante de tensões, ganham corpo e sentido partilhados todo o tempo. Numa análise de texto, o rastreamento dos interlocutores, as posições na enunciação e os lugares da cena posta na e pela análise, carecem desse movimento ao vivo das respostas e reações. No entanto, entre analista e texto analisado, contam, sim, as expectativas do primeiro em relação ao corpus, ao autor. Contam também as cenas das interlocuções no interior do mesmo (Guirado, 2006).

Como se pode prever, a análise do discurso de um texto de Freud, portanto, irá identificar (a) o modo como ele apresenta a discussão que será feita, (b) que estatuto atribui ao conhecimento produzido pela publicação de um atendimento clínico, (c) como apresenta e/ou reformula suas hipóteses conceituais, (d) que lugar ocupa o cliente nesse processo, (e) que lugar atribui a si próprio como médico-analista, à psicanálise como tratamento, e assim por diante. Desse modo, poder-se-ia chegar a qualificar, ou melhor, a "fazer o desenho" de como Freud monta ou remonta o conceito de inconsciente num determinado texto; como potencializa as questões de tempo, espaço, história, desenvolvimento, biologia, para tratar do Homem dos Lobos, exemplar no redesenho de seu inconsciente (de Freud). Para isso, não poderíamos proceder à análise de seu escrito, com um conhecimento ou um saber (pressuposto e "simpático", endógeno à teoria freudiana) que antecipasse e, com isso, vedasse qualquer possibilidade de restituir ao seu discurso, o caráter de acaso, de acontecimento. O conceito de 
inconsciente estaria no ponto de partida e, por tabela, como que num passe de mágica-imaginária do reconhecimento-legitimador, no horizonte das conclusões da pesquisa. E não, como se costuma afirmar com ares de descoberta, no resultado da análise.

Desta feita, operar uma análise institucional do discurso Freudiano sobre a clínica não só dispensa, como também, impede que se pense, a priori, com o conceito freudiano de inconsciente. É uma questão de princípio metodológico, de estratégia de pensamento. A atenção se volta exatamente para o modo como Freud pensa o inconsciente. Ficamos impedidos de fazer isso (porque imediatamente envolvidos e comprometidos), quando partimos do próprio conceito que estamos estudando, como se ele estivesse, naturalmente, acima de qualquer suspeita, fosse a própria coisa, fosse a verdade, no caso, sobre a vida do Homem dos Lobos.

Chegar-se-ia lá mesmo (de) onde se partiu. Isto porque os fins estariam no começo, de forma opaca, enviesada, ou, numa linguagem psicanalítica, de forma perversa. Mas o que é mais complicado (seja lá pelo argumento que for, como esse de que se faria uma crítica exterior, uma crítica que não respeitaria a ordem interna do discurso da clínica) é que não se avança, não se sai do plano do comentário, da repetição do mesmo, com estudos assim endógenos, antropofágicos. Ain- 
da que cercado de rituais de pompa e circunstância, ainda que pronunciado pelos ungidos, ainda que autorizado ao grupo seleto dos que podem dizêlo, esses discursos que resultam dessa vontade de verdade, reforçam o caráter instituído do conhecimento e da pesquisa e afastam, mais e mais, a condição de acaso e indeterminação do discurso da e sobre a clínica psicanalítica (no caso).

O título deste subitem diz disso tudo com termos psicanalíticos. Mais literário, menos argumentativo, pode agora ser retomado, pois não se desperdiçará, em sua vocação para a metáfora, seu compromisso conceitual: o estranbamento é a condição de análise; talves, seu limite inevitável.

Creio ter podido contribuir com a discussão que ronda as interdições às possibilidades de analisar os discursos da psicanálise, ou mesmo de exercê-la (Guirado, 2010), sem que seja estritamente do interior de suas práticas e recursos conceituais.

A POSSIBLE ANALYSIS OF THE PSYCHOANALYSIS'S DISCOURSE

\footnotetext{
Abstract

The discussion deals with a concrete situation of a negative evaluation by a scientific Foundation, on a research project about an institutional analysis of the discourse of Freudian's Wolf Man, one of the most famous psychoanalytic studies. The argument to the refusal was that the methodology of the project didn't fit to psychoanalysis theory. The arguments against this criticism are supported by a concept of
} 
discourse as act, institution, so to affirm that being surprised by the discourse is the fundamental analysis condition, or even its inevitable frontier. It makes possible going on thinking and researching, although that kind of evaluation procedure has harmful immediate effects on our intellectual production.

Index terms: analysis of discourse; psychoanalysis; power; knowledge.

\section{UN ANÁLISIS POSIBLE DEL DISCURSO DEL PSICOANÁLISIS}

\section{RESUMEN}

Este articulo aborda el contexto especifico en el que se le negó una beca, a pesar de los conceptos erróneos del parecer acerca de la metodología (análisis institucional del discurso), ya que esta no contemplaría la teoría psicoanalítica, cuando el discurso en cuestión es el Hombre de los Lobos, de Freud. Los argumentos se ponen juntos, desde la concepción del lenguaje como acto, evento y como institución, con el fin de hacer valer el extrañamiento como condición para (de) el análisis; quizá su limite inevitable. Así, se convierte posible seguir pensando, a pesar de los efectos inmediatos de estos procedimientos de evaluación en/de nuestra producción intelectual.

Palabras clave: análisis del discurso; psicoanálisis; poder; verdad.

\section{REFERENNCIAS}

Austin, J. L. (1990). Quando dizer é fažer. Porto Alegre: Artes Médicas.

Foucault, M. (1997). Arqueologia do saber. Rio de Janeiro: Forense. (Trabalho original publicado em 1969)

Foucault, M. (1999). A ordem do discurso. São Paulo: Loyola.

Foucault, M. (2004). Ditos e escritos V. Rio de Janeiro: Forense Universitária.

Freud, S. (2010). História de uma neurose infantil. (P. C. Souza, trad.). São Paulo: Companhia das Letras. (Trabalho original publicado em 1918)

Guirado, M. (2000). A clinica psicanalitica na sombra do discurso. São Paulo: Casa do Psicólogo.

Guirado, M. (2006). Psicanálise e Análise do Discurso: matrizes institucionais do sujeito psíquico. São Paulo: EPU. (Trabalho original publicado em 1995)

Guirado, M. (2010). Análise Institucional do Discurso como analítica da subjetividade. São Paulo: Annablume/FAPESP.

Maingueneau, D. (1997). Introdução à Linguística. Lisboa: Gradiva.

Guirado, M. (2000). Aula sobre discurso e Análise do Discurso. In M. Guirado, $A$ clínica psicanalitica na sombra do discurso. São Paulo: Casa do Psicólogo.

Marcondes, D. (2004). Filosofia analítica. Rio de Janeiro: Jorge Zahar.

Wittgenstein, L. (1999). Investigacõoes filosóficas. São Paulo: Nova Cultural. (Trabalho original publicado em 1952) 


\section{Dossiê}

\section{NOTAS}

1 Felipe Martins, autor do Projeto de IC "Clínica e Discurso: uma análise do texto $O$ homem dos Lobos de Freud", atualmente com Bolsa CNPq (2010/2011).

mguirado@terra.com.br

Recebido em janeiro/ 2011. Aceito em maio/2011. 